Article

\title{
Evolution of a Development Model for Fruit Industry Against Background of Rising Labor Cost: Intensive or Extensive Adjustment?
}

\author{
Bin Yuan ${ }^{1}$ and Chao Chen ${ }^{2, *}$ \\ 1 College of Management, Ocean University of China, Qingdao 266100, China \\ 2 College of Economics and Management, Nanjing Agricultural University, Nanjing 210095, China \\ * Correspondence: cchen@njau.edu.cn; Tel.: +86-25-8439-6687
}

Received: 6 June 2019; Accepted: 13 July 2019; Published: 16 July 2019

\begin{abstract}
As an important starting point for optimizing the structure of agricultural products and implementing green production methods, the direction of orchard management development is directly related to the success of "supply side" reform in the fruit industry in China. However, in the context of the progressive rise of labor force, is the labor force still capable of the high labor intensity and fine cultivation management needed, such as for pruning? In this paper, based on the micro-production data of peach farmers in different provinces, we set up a decision model of fruit trees management to analyze the effects of changes in the labor cost on orchard management's input for farmers with different trading characteristics under the information asymmetry theory. The results show that with the increase of labor force cost, although the total labor investment of farmer households has somewhat reduced, significant differences exist in the distribution of labor investment between the different farmers due to the different labor demands from the various trading characteristics. By repeated transactions that transmit information of quality, farmers can get a high marginal price of fruit, and these relatively repeated transactions further increase the labor investment of fine management. Foreseeably, the rising of rural labor cost will have a negative impact on fine cultivation management in the fruit and nut industries, which have the same management methods for pruning and flower (fruit) thinning. Therefore, this paper offers relevant policy recommendations for the support of agriculture products brand, optimization of production tools, expansion of operation scale, and the establishment of networks of companies, aimed at sharing skilled labor for the execution of quality work, etc.
\end{abstract}

Keywords: management mode; economic sustainability; ecological sustainability; labor cost

\section{Introduction}

As a backbone industry that alleviates poverty in vast rural areas and creates wealth for farmers, China's fruit industry has long maintained a rapid growth trend. The fruit industry has become China's third largest agricultural cultivation industry after food crops and vegetables. However, fertilizer application in the fruit cultivation process has also increased sharply. In 2014, the total amount of fertilizer applied in fruit cultivation in the country had reached 543.5 million tons, far higher than the 398.1 million tons used on crops and the 203.4 million tons used on corn, and it is still maintaining a rapid growth rate. Therefore, how to further optimize the structure of fruit products, promote a transition to green production modes, and further improve the efficiency of chemical fertilizers to achieve zero growth in fertilizer usage are significant for enhancing the capacity for the sustainable development of agriculture and achieving "supply side" reform of the fruit industry. At the same time, China's rural labor income is rapidly increasing. Existing studies have almost unanimously agreed that 
China will face serious labor cost problems in the future. In addition, given the differences in the rate of agricultural participation among the different genders, age groups, and health conditions, a significant decline will occur in the number of workers that are truly engaged in agricultural production. Therefore, the changes and trends in the agricultural labor cost will have a profound impact on rural development and agricultural production. Some scholars have argued that farmers that plant labor-intensive horticultural crops should not only ease labor constraints, but also improve quality of product through fine management faced with the rising of the labor cost. When the needs of different consumers are satisfied, so is the farmers' income [1]. However, the effect of labor cost shows significant differences. Taking peach planting farmers as an example, in the face of rising labor prices, some farmers have to reduce the labor input of fine management and choose a more extensive management mode, while others can still maintain or even improve the original orchard fine management input.

The focus of the existing research is mainly on the analysis of the impact of the labor cost on food production but it ignores the impact on fruit production, which is more labor-intensive. With the continued increase in the application of chemical and organic fertilizers and pesticides in fruit cultivation, farmers should invest more labor force in the pruning and thinning of flowers (fruits) to the effective usage of chemicals. Meanwhile, it is difficult for consumers to accurately determine the quality of agriculture products in their purchase process. Therefore, in order to reduce the risk of "mis-selection", consumers usually buy products at a lower price, leading to the phenomenon of "adverse selection" [2,3]. The "volume gap" has been further narrowed or even disappeared, resulting in the weakening of the incentives of suppliers improving product quality [4-6]. Therefore, this study considers peach farmers in different provinces as an example and analyzes the effect of the rising labor cost on the input of fine management by studying the pruning and thinning of flowers and fruits. Notably, based on the perspective of labor cost and external endowment of farmers, this paper systematically analyses the decision-making mechanism of the transformation of farmers' production management mode. Furthermore, the improvement of research methods enhances the persuasiveness and reliability of the research results.

\section{Theoretical Framework}

As a technology of production and cultivation aiming at obtaining higher economic, ecological, and social benefits, fine management is a combination of a series of management techniques, including artificial pruning, thinning of flowers (fruits), and so on. The fine management techniques are the core issues of maintenance of fruit quality and production stability, which require intensive labor and have labor-intensive properties. The labor cost accounts for absolute parts of the fine management techniques cost. Existing studies have almost unanimously agreed that the substitution of factor and product, respectively, are both approaches to the rise of labor cost. Furthermore, long-term practice has proven that the degree of substitution between factors was constrained by technological and economic foundation [7].

Unlike traditional field crops, the development of fruit trees in different growth periods is often unbalanced under natural conditions. If fruit trees grow too fast, they are more likely to fruit only in alternate years or to fruit excessively, reducing the commercial value and profits of fruit tree cultivation [8]. Therefore, in managing fruit trees, usually artificial pruning, thinning of flowers (fruits), and other fine management techniques are applied to balance the relation between vegetative growth and reproductive growth, thus contributing to the absorption of fertilizers and the maintenance of fruit quality and production stability. However, due to the lack of depth of integration between agricultural machinery and agronomy in China, fine management techniques, such as the pruning and thinning of flowers and fruits, are mainly achieved by manual sawing and cutting by laborers who must also climb ladders and hills [9-11]. These efforts require intensive labor and have certain safety risks [12]. Therefore, from the mode and characteristic of technology usage, the pruning and thinning of flowers (fruits) and other fine management techniques clearly have labor-intensive properties, and the degree of investment depends almost entirely on the amount and quality of labor investments [13]. Under 
the existing technical conditions, fine management techniques that center on pruning and thinning of the flowers and fruits are still unable to realize an effective substitution of machinery for the human labor force.

Compared with factor substitution, the substitution of product seems to be more suitable for fruit farmers. Due to the constraints of empirical attributes for agricultural products, it is often difficult for agricultural products to be sold at corresponding price, especially high-quality agricultural products. Owing to the multiple harvest in different batches, transactions are frequently encountered between fruit farmers. The statistical results of the sample farmers in Table 1 show a high-frequency trading state, where farmers made more than 60 trades a year and the trading frequency was 1.35 times a day on average.

Table 1. Description and analysis of the transaction status of farmers.

\begin{tabular}{cccc}
\hline \multicolumn{2}{c}{ Number (Times) } & \multicolumn{2}{c}{ Frequency (Times/Day) } \\
\hline Mean & $\mathbf{6 2 . 3 6}$ & Mean & $\mathbf{1 . 3 5}$ \\
\hline Distribution (Times) & Percentage (\%) & $\begin{array}{c}\text { Distribution } \\
\text { (Times/Day) }\end{array}$ & Percentage (\%) \\
\hline Under-30 & 5.03 & $0.1-0.3$ & 6.04 \\
$31-39$ & 6.81 & $0.4-0.6$ & 14.39 \\
$40-49$ & 15.04 & $0.5-0.9$ & 22.20 \\
$50-59$ & 25.93 & $1.0-1.2$ & 34.40 \\
$60-69$ & 22.56 & $1.3-1.5$ & 7.16 \\
$70-79$ & 17.23 & $1.6-1.8$ & 6.57 \\
Above-80 & 7.40 & Above-1.8 & 9.24 \\
Total sample & 100 & Total sample & 100 \\
\hline
\end{tabular}

With the increase of successful transactions, the customer gets more trust-related information, and thus has a stronger judgment about trust. On one hand, the selection of trading objects and success rate of transactions between wholesalers, brokers, and other intermediaries with farmers largely depends on the past transaction records under the condition of incomplete symmetry of market information. On the other hand, farmers with good transaction records or reputation are more likely to urge wholesalers and make a deal under the influence of reputation mechanism. Furthermore, dealers can form a relatively stable expectation about product quality, and good reputation is also regarded as the endorsement of product quality. Therefore, farmers with good reputation can still sell fruits at a higher price than farmers with low reputation in the same situation. In order to further the theoretical analysis, this paper assumes that there are two types of farmers producing high-quality and low-quality fruits, and net income of peach cultivation are shadow A and B. These two are equal to each other at equilibrium state. With the increase of proportion of repeated transactions, the discount will be narrowed, caused by "asymmetric quality information". The price of high-quality agricultural products is up from PH1 to PH2, which will enable farmers to obtain higher net income from high-quality agricultural products (the area of shadow expands from A to C; see Figure 1).

At the same time, the repeated transactions often depend on a series of features of farmers, such as good interpersonal relationship of farmers, providing better services for buyers, or establishing brands in order to facilitate the identification of purchasers, thus inevitably increasing the sales cost of farmers. The features of farmers not just require additional charges, but also lead to a different share of production cost, especially the decreases of cost share of fine management techniques that require intensive labor and have labor-intensive properties. The different share of labor cost leads to the variations of average total cost. When labor cost rises, the increase of the average production cost of high-quality fruits (the average cost curves change from $\mathrm{AC}_{\mathrm{H}}$ to $\mathrm{AC}_{\mathrm{H}}^{\prime}$ ) is less than that of the low-quality fruits (the average cost curves change from $A C_{L}$ to $A C^{\prime}{ }_{L}$ ), as shown in Figure $1 \mathrm{~b}$. 


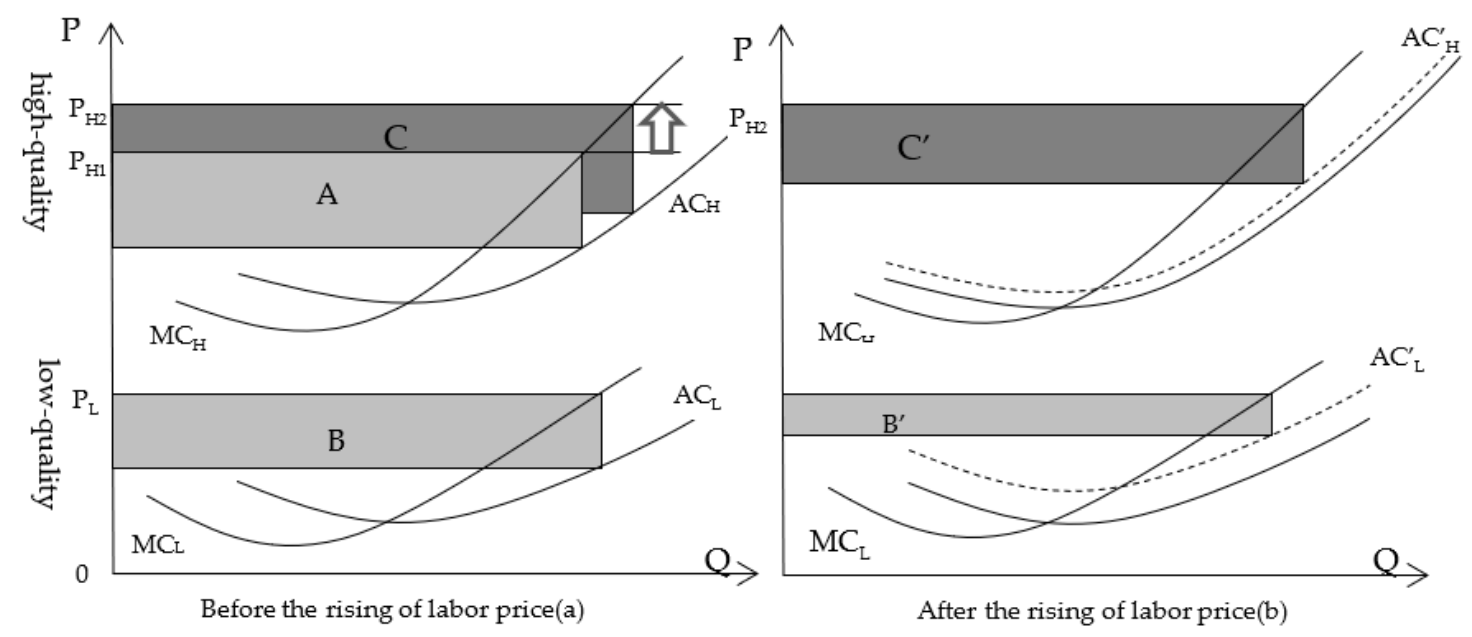

Figure 1. The relation between labor cost and decision of agricultural quality.

Therefore, based on the standard farmer model, this study further constructs a dynamic effect model to explore the effect of rising of labor cost on investment in technical aspects, to reflect the impact of the labor cost on the farmers with different repeated transactions. The specific model is as follows:

$$
\pi=P(H)(1-\delta+\lambda) \cdot Q-C(Q)-L \cdot P_{L}-C(\lambda) ; H(L, x)
$$

In the above, $\pi$ is the total production income. $C(Q)$ is a cost function of the fruit production and $P_{L}$ is the unit cost of labor. $H(L, x)$ is an input function of the amount of labor invested by the farmer $L$ and the technological level of famer $X$. With the increase in fine management techniques input, the utility of the unit labor gradually reduces; that is, $H^{\prime}(L)>0, H^{\prime \prime}(L)<0 \quad[14,15]$. In addition, $P(H)$ is a function of prices of different quality of agricultural products, which depends on the change of supply and demand.

In order to facilitate the following analysis, this paper assumes that the supply and demand of agricultural products of different quality levels are certain. With the improvement of quality, the unit price of quality gradually increases; that is, $P^{\prime}(H)>0 \quad P^{\prime \prime}(H)>0$. As a result of rationality, consumers will not excessively pay for a product of high quality and the marginal effect of the degree of technical investment follows the degression law; that is $P^{\prime \prime}(H)<0 \quad[16,17]$. Since the market information has a strong asymmetry, it endows consumers with no full power to identify price, which makes them pay a lower price for product so as to reduce the risk of buying by mistake. The paper defines a coefficient of $\delta$ which is the chances of buying by mistake and $0<\delta<1$. $\lambda$ is the overflow benefit merited by lessening negative influences of information asymmetry and improving quality of information transmission.

According to the model and hypotheses, $L$ is further derived as follows:

$$
\begin{gathered}
\delta \pi / \delta L=P^{\prime}(L) \cdot(1-\delta+\lambda) \cdot Q-P_{L}=0 ; P_{L}=P^{\prime}(L) \cdot(1-\delta+\lambda) \cdot Q \\
\delta P_{L} / \delta L=\left[P^{\prime \prime}(H) \cdot H^{\prime}(L)^{2}+P^{\prime}(H) \cdot H^{\prime \prime}(L)\right] \cdot(1-\delta+\lambda) \cdot Q
\end{gathered}
$$

We can define that $g=\delta P_{L} / \delta L$ and then further deduce the following:

$$
\begin{aligned}
& \frac{\delta g}{\delta \delta}=\frac{1}{\left[P^{\prime \prime}(H) \cdot H^{\prime}(L)^{2}+P^{\prime}(H) \cdot H^{\prime \prime}(L)\right] \cdot Q \cdot \delta^{2}}<0 \\
& \frac{\delta g}{\delta \lambda}=\frac{-1}{\left[P^{\prime \prime}(H) \cdot H^{\prime}(L)^{2}+P^{\prime}(H) \cdot H^{\prime \prime}(L)\right] \cdot Q \cdot \lambda^{2}}>0
\end{aligned}
$$


Therefore, we can derive that the increase in the labor cost will make farmers reduce labor investments in pruning and flower/fruit thinning. In addition, the impact of the labor cost on the farmers' investments in pruning, etc., depends on the chances $\delta$ of buying by mistake and overflow benefit merited by lessening these negative influences of information asymmetry and other factors. With the increase of chances of consumer purchasing by mistake, the negative effects of labor cost on investments in pruning and flower/fruit thinning will expand. At the same time, farmers can minimize negative impact of labor cost through overflow benefit merited by lessening negative influences of information asymmetry. We can derive that the large overflow benefit will offset the negative impact of labor cost.

\section{Model Description and Data Analysis}

\subsection{The Impact of Labor Cost on Technological Investment}

According to the framework of the above analysis, this study analyzes the effect of labor cost on technological investment by examining cross-section data and thus does not consider the individual effect and time effect of the model. The empirical model of the effect of labor cost on labor investment can be set as follows:

$$
H_{i}=\alpha+\lambda w+N_{i}+\beta_{1} N_{i}+\beta_{2} \text { old }+\theta M_{i}+\gamma D_{i}+e_{i}
$$

$H_{i}$ represents the fine management mode of the i-th farmer, expressed by the degree of labor investment of farmer in pruning and thinning of flowers (fruits). The key explanatory variables of this study include following two parts. The first key explanatory variable $w$ is the price of labor expressed by daily wages. $N_{i}$ represents the degree of repeat transactions. It should be noted that peach farmers not only sell fruit frequently, but also have a wide range of sales object such as brokers, intermediary purchasers, and so on. Because of the relatively limited purchase quantities, a wider range of sellers and long purchase periodicity, the repeated transactions often fail to effectively convey the information of peach quality to purchaser between farmers and consumers. Based on this, this paper only selects samples that mainly deal with wholesalers, brokers, and other intermediaries with trading share of more than 50 percent. Thus, $N_{i}$ is expressed by the number of trades between farmer and the most heavily traded dealer. The dummy variable old represents the degree of aging of the agricultural labor force and the labor force is further divided into two groups: 60 years old and below (old = $)$ ) and above-61 group (old =1). $M_{i}$ and $D_{i}$ are control variables referring to the existing research [18-20]. The variable $M_{i}$ is family and individual characteristics to account for the heterogeneity of the farmers-that is, the number of people in the labor force, number of technical training sessions attended, share of peach cultivation income and number of years engaged in peach cultivation from beginning to the present. $D_{i}$ represents production characteristics-the amount of land, whether they participated in cooperatives rendering services, planting density, and the age of peach trees.

Model (6) focuses on analyzing the effect of labor cost on investment of fine management, reflecting the pulling effect of external premium and overlooking the heterogeneity of the different farmers in terms of transaction characteristics. Therefore, this study tries to build a new variable, which is the interactive item of $N_{i} \times w$, analyzing the heterogeneity of labor cost on farmers with different transaction characteristics. The final model is as follows:

$$
H_{i}=\alpha+\lambda N_{i}+\delta_{i}\left(N_{\mathrm{i}} \times w\right)+\beta_{1} \text { old }+\beta_{2} w+\theta M_{i}+\gamma D_{i}+e_{i}
$$

\subsection{Analysis of Endogenous Problems}

The high-quality peach mainly depends on the investment of the labor force, and likely attracts customers to buy peaches time and time again. Therefore, if we treat the degree of repeat transactions as the dependent variable, endogenous problems seem to arise with the model. Because of the large 
number of population and scarce land resources, small-scale peasant mode of operation reduces the market negotiating position of farmers in dealing with traders, organizations, and enterprises in China [21,22]. Importantly, the major contradiction of agriculture has changed from insufficiency in total volume to poor balance of the provision system in China. Therefore, the repeat transactions are given as an initiative behavior of farmers [23,24]. The survey data also shows that the greatest sources of repeat transactions is an appropriate price for peaches from the subjective inference of farmers, which accounts for $76.14 \%$ of total sample peasant households. However, only $6.16 \%$ of peasant households believed that the cause of repeated transactions was the high quality of peaches. Therefore, this study tries to avoid endogenous problems by constructing a simultaneous equations model of labor force investment and repeat transactions, highlighting the overall characteristics of the estimated parameters. The models are set as follows:

$$
\left\{\begin{array}{l}
H_{i}=f\left(N_{i}, X_{i}, M_{i}, D_{i}\right) \\
N_{i}=g\left(H_{i}, T_{i}, K_{i},\right)
\end{array}\right.
$$

According to previous research, factors influencing degree of repeat transactions can be divided into two categories [25-27]. The first variable $K_{i}$ is product features- that is, the sales time of peaches, the input of organic fertilizer, whether they possessed regional public or independent brands, and the average selling price of peaches. The second variable $\left(T_{\mathrm{i}}\right)$ is characteristics of purchasers, which is expressed by the concentration of dealers ( $h$ hi) calculated by the Herfindahl index. In the calculation formula, a variable $(n)$ of the type of different dealers can be divided into six categories: general consumers, mobile traders, brokers, wholesalers, cooperatives, and enterprises. $X$ represents the total sales quantity of peaches and $X_{i}$ indicates the amount of peach sale in the process. The specific indicators are set as follows:

$$
h h i=\sum_{i=1}^{n}\left(X_{i} / X\right)^{2}
$$

\subsection{Data Source and Description}

According to the peach production, acreage, and farmer household income levels of the different main producing areas in 2017, we picked 18 prefecture-level provinces, plus 20 experimental stations (towns), and 100 villages as our sampling region by using system sampling and K-means Cluster. The method of sample selection can be divided into two categories: First, we selected five sample counties from each test station (region) according to the peach planting situation; second, we further randomly selected 100 peach farmers from each county according to the questionnaire. The contents of the questionnaire included basic demographic data for cultivation area of the peach trees, the number of years engaged in peach cultivation from beginning to the present, use of technology, the individuals and families, whether they participated in cooperatives rendering services, and investment of the key elements. After removal of the invalid samples, a total of 1786 valid questionnaires were obtained. Table 2 presents the description and definition of variables.

Table 2. Description and definition of variables.

\begin{tabular}{lccccc}
\hline \multicolumn{1}{c}{ Variable } & Symbol & Mean & $\begin{array}{c}\text { Standard } \\
\text { Deviation }\end{array}$ & Min & Max \\
\hline Investment of fine management (worker/mu) & $H$ & 18.078 & 34.537 & 7.272 & 46.8 \\
Degree of repeat transactions (time) & $N$ & 13.594 & 21.302 & 1 & 62 \\
Price of labor (yuan/mu) & $w$ & 193.738 & 51.170 & 100 & 400 \\
Number of people in the labor force (number) & lab & 4.246 & 1.879 & 1.879 & 8 \\
Number of training (number) & tec & 1.259 & 1.264 & 0 & 6 \\
\hline
\end{tabular}


Table 2. Cont.

\begin{tabular}{lccccc}
\hline \multicolumn{1}{c}{ Variable } & Symbol & Mean & $\begin{array}{c}\text { Standard } \\
\text { Deviation }\end{array}$ & Min & Max \\
\hline Experience for plantation (year) & time & 17.634 & 9.042 & 3 & 40 \\
Share of cultivation income (\%) & inc & 0.545 & 0.308 & 0.075 & 1 \\
Elder group & old & 0.574 & 0.495 & 0 & 1 \\
Education level & edu & 1.980 & 0.582 & 1 & 4 \\
Risk preferences & risk & 2.36 & 1.17 & 1 & 4 \\
Plant area (mu) & size & 6.184 & 7.557 & 0.9 & 50 \\
Age of peach tree (year) & age & 8.611 & 3.829 & 2.6 & 22.5 \\
Plant Density (number/mu) & den & 38.402 & 6.776 & 14.473 & 61 \\
Type of farmer & type & 0.936 & 0.245 & 0 & 1 \\
East regions & pla 1 & 0.451 & 0.498 & 0 & 1 \\
Central regions & pla & 0.368 & 0.483 & 0 & 1 \\
Concentration of dealers & hhi & 0.816 & 0.215 & 0.24 & 1 \\
Regional public or independent brands & bra & 0.871 & 0.335 & 0 & 1 \\
Input of organic fertilizer (yuan/mu) & org & 820.551 & 524.957 & 0 & 2500 \\
Sales time of peaches (day) & per & 63.355 & 105.635 & 35 & 93 \\
Average selling price (yuan/kg) & pri & 10.136 & 3.723 & 1 & 19.245 \\
\hline
\end{tabular}

\section{Results}

\subsection{Selection of Estimation Method}

As the results shown in Tables 3 and 4, the premise for estimation of simultaneous equations is the identifiability of the total estimating parameters. The identifiability of the equations can be divided into two dimensions: whether the parameters can be identified and how identifiable it is. First, there are 21 exogenous variables and 2 endogenous variables in the overall simultaneous equations. Among them, there are 15 exogenous variables and 2 endogenous variables in the model of household fine management. There are 6 exogenous variables and 2 endogenous variables in the model of repeat transactions. Therefore, both models are identifiable and have characteristics of over-recognition from the results of rank condition in the model.

Table 3. Identifiability of simultaneous equations.

\begin{tabular}{ccc}
\hline Simultaneous Equations & $\boldsymbol{H}_{\boldsymbol{i}}$ & $\boldsymbol{N}_{\boldsymbol{i}}$ \\
\hline Number of endogenous variables of system $(\mathrm{g})$ & 2 & 2 \\
Number of exogenous variables of system $(\mathrm{k})$ & 21 & 21 \\
Number of endogenous variables of subsystem $\left(g_{1}\right)$ & 2 & 2 \\
Number of exogenous variables of subsystem $\left(k_{1}\right)$ & 15 & 6 \\
$\operatorname{rank}\left(F_{0}, \Gamma_{0}\right)$ & 1 & 1 \\
$k-k_{1}$ & 6 & 15 \\
$g_{1}-1$ & 1 & 1 \\
\hline
\end{tabular}

According to existing research, the methods of simultaneous equations estimation are divided into single equations estimation and full information estimation. The efficiency of estimator can also be improved by full information estimation including Three Stage Least Square (3SLS) and Generalized Method of Moments (GMM). The result of the Hausman Specification Test shows that residual coefficients are not all equal to zero. The Three Stage Least Square (3SLS) is better than the Generalized Method of Moments, and was used to estimate simultaneous equations. 
Table 4. The result of Hausman specification test.

\begin{tabular}{cccccc}
\hline $\begin{array}{c}\text { Residual } \\
\text { Error }\end{array}$ & Model & Estimate & Standard Error & T-Values & P-Values \\
\hline$\hat{\varepsilon}_{H}$ & $H_{i}$ & 2.0121 & 0.5201 & 3.87 & 0.0001 \\
$\hat{\varepsilon}_{N}$ & $N_{i}$ & 0.2341 & 0.0798 & 2.93 & 0.0036 \\
\hline
\end{tabular}

\subsection{Estimation of the Effect of Repeat Transactions on Farmers' Technical Investments}

The estimation results of specific models are presented in Table 5. Both the result of Ordinary Least Square model and the simultaneous equations model show that the estimated coefficient of degree of repeated transactions (Ni) is significantly positive and the estimated coefficient of labor cost $(w)$ is significantly negative. The above empirical results verified to a certain extent the hypothesis of this study; that is, as the labor cost increases, farmers will significantly reduce amount of labor invested in technical processes. By contrast, the degree of repeated transactions has a direct positive effect on labor investment. Both ordinary consumers and brokers, wholesalers, and other intermediary purchasers, can identify quality of peaches or get feedback on quality after buying fresh peaches from farmers. More importantly, owing to cultivation characteristics of fresh peaches, the possibility of repeated transactions was also greatly improved. Therefore, the increase in the degree of repeated transactions can not only transfer information of peach quality to the purchaser and lessen the negative effect of information asymmetry, but also form potential reputation for quality and bring reasonable quality premium.

Although the phenomenon of "Free Rider" or "Sells Seconds" may generate higher returns, farmers will miss follow-up opportunities to cooperate and lose all benefits of future deals within the constraints of the reputation for quality. According to the above analysis, farmers cannot obtain higher returns than with the production of high-quality peaches. With the rising level of consumption demand and upgrading transition of fruit industrial structure, the increase of repeated transactions can greatly transmit information of peach quality and reduce motivation to produce low-quality products, ensuring that farmers can obtain higher income with high-quality peach and increasing amount of labor invested in technical processes.

Table 5. Estimated results of the impact of repeated transactions.

\begin{tabular}{|c|c|c|c|c|c|}
\hline \multirow{2}{*}{ Variable } & \multirow{2}{*}{ Symbol } & \multicolumn{2}{|c|}{ OLS } & \multicolumn{2}{|c|}{ 3SLS } \\
\hline & & Coefficient & $T$-Values & Coefficient & $T$-Values \\
\hline \multicolumn{6}{|c|}{ 1. Investment of Fine Management Function Estimate } \\
\hline Degree of repeat transactions & $N$ & 0.0277 & -0.66 & $0.207 *$ & -1.65 \\
\hline Price of labor & $w$ & $-0.035^{* *}$ & -2.54 & $-0.038^{* * *}$ & 2.70 \\
\hline Elder group & old & 0.716 & -0.65 & 0.862 & -0.78 \\
\hline Number of people in the labor & $l a b$ & $2.534^{* * *}$ & -10.96 & $2.526^{* * *}$ & -10.92 \\
\hline Education level & $e d u$ & -0.698 & -1.31 & -0.821 & -1.51 \\
\hline Number of training & tec & 0.822 & -0.81 & 0.628 & -0.61 \\
\hline Experience for plantation & time & $0.130 * *$ & -2.00 & 0.0914 & -1.25 \\
\hline Share of cultivation income & $i n c$ & -0.127 & -0.14 & -0.281 & -0.30 \\
\hline Risk preferences & risk & -0.494 & -1.33 & -0.464 & -1.25 \\
\hline Type of farmer & type & -0.004 & -0.73 & -0.004 & -0.75 \\
\hline Plant area & size & 1.232 & -1.28 & 0.971 & -0.97 \\
\hline Age of peach tree & age & $0.314^{* * *}$ & -2.75 & $0.370 * * *$ & -2.98 \\
\hline Plant Density & den & 0.015 & -1.28 & 0.015 & -1.29 \\
\hline East regions & $p l a_{1}$ & $3.925^{* * *}$ & -3.18 & $4.125^{* * *}$ & -3.30 \\
\hline Central regions & $\mathrm{pla}_{2}$ & -0.142 & -0.11 & 0.329 & -0.24 \\
\hline Constant & _cons & $-1.871^{* * *}$ & -2.64 & $-2.671^{* * *}$ & -2.91 \\
\hline R-squared & & \multicolumn{2}{|c|}{0.6326} & \multicolumn{2}{|c|}{0.6536} \\
\hline Prob $>$ F & & \multicolumn{2}{|c|}{0.0000} & \multicolumn{2}{|c|}{0.0000} \\
\hline
\end{tabular}


Table 5. Cont.

\begin{tabular}{|c|c|c|c|c|c|}
\hline \multirow{2}{*}{ Variable } & \multirow{2}{*}{ Symbol } & \multicolumn{2}{|c|}{ OLS } & \multicolumn{2}{|c|}{ 3SLS } \\
\hline & & Coefficient & $T$-Values & Coefficient & $T$-Values \\
\hline \multicolumn{6}{|c|}{ 2. Degree of Repeat Transactions Function Estimate } \\
\hline Investment of Fine Management & $\mathrm{H}$ & -0.003 & -0.22 & -0.046 & -1.00 \\
\hline Sales time of peaches & per & $0.153^{* * *}$ & -15.95 & $0.156^{* * *}$ & -15.73 \\
\hline Input of organic fertilizer & org & -0.001 & -1.55 & -0.001 & -1.15 \\
\hline Average selling price & pri & -0.023 & -0.29 & -0.022 & -0.28 \\
\hline $\begin{array}{l}\text { Regional public or independent } \\
\text { brands }\end{array}$ & bra & 1.420 * & -1.72 & $1.493 *$ & -1.80 \\
\hline Concentration of dealers & $h h i$ & -0.049 & -0.09 & -0.011 & -0.02 \\
\hline Constant & _cons & $2.856^{* * *}$ & -3.5 & $3.126^{* * *}$ & -3.55 \\
\hline R-squared & & \multicolumn{2}{|c|}{0.7124} & \multicolumn{2}{|c|}{0.6856} \\
\hline Prob $>$ F & & \multicolumn{2}{|c|}{0.0000} & \multicolumn{2}{|c|}{0.0000} \\
\hline
\end{tabular}

\subsection{Estimation of the Effect of Labor Cost on Farmers' Technical Investments with Differernt Degree of Repeat Transactions}

According to the results of heterogeneous regression, the above empirical results verified to a certain extent the hypothesis of this study; that is, the interaction coefficient of labor cost and degree of repeat transactions were significant at the $1 \%$ confidence levels, so we can still consider that in most cases, for farmers with relatively lower degrees of repeat transactions, as labor cost increases, they will significantly reduce their labor investment in fine management. The reasons are chiefly as follows: Firstly, with the increase of labor cost, the degree of repeated transactions can greatly transmit quality information of peaches and reduce motivation to produce low-quality products, ensuring that farmers can obtain higher income by producing high-quality peaches. In addition, as important causes of repeat transactions, packaging, brands, and establishment of partnership consume a great deal of manpower, materials, and finance, reducing the share of labor cost. Therefore, as the labor cost increases, the income of farmers with relatively lower degrees of repeat transactions will significantly reduce.

\subsection{Estimation of the Impact of Degree of Repeat Transactions}

The estimation result of the degree of repeat transactions are presented in Table 6. It shows that the coefficient of investment of fine management in both OLS model and 3SLS model did not pass the significance test. In other words, with an increase of labor investment in fine management, the degree of repeat transactions will not be improved, mainly depending on the estimated quality of peach.

The coefficients of sales time and brands of peach are 0.069 and 0.382 , respectively, and the corresponding significance levels of the models are all 0.00 . That is, they have shown to a certain extent that with the increase of sales time and brands of peach, the number of transactions will increase, further improving the degree of repeat transactions. Being a medium for transmitting information, on one hand, the brand of agricultural product effectively differentiates peaches of different quality and transmits information of peaches' quality, helping consumers to purchase peaches according to their preference. On the other hand, the emergence of brand can not only reduce perceived risk of purchasing behavior and improve consumers purchasing motive of buying branded products under the same risk conditions, but also ultimately form consumers' loyalty to the brand. Therefore, compared with others, farmers owning a private or regional public brand of peach have more degree of repeated transactions with sales objects.

As an important way of improving quality of peach, the input of organic fertilizer did not have a significant impact on the degree of repeated transactions. As a result of difficulties of building brands and poorer identifiability of quality, it is difficult for farmers to make the quality of peach obtain the 
approval of consumers and improve probability of repeated transactions. In addition, the asymmetrical information of quality significantly reduces consumer price sensitivity. Although the increase of prices will reduce the satisfaction of buyers, the behaviors of repeated purchasing more strongly relate to the perceived value of products [28]. Therefore, the estimated coefficient of sales price has not passed the significance test. From the estimation results of the model and based on the perspective of improving the degree of repeat transactions, the contract is undoubtedly the best option due to prior fixed transaction objects. However, because of the disputes with contracting parties about risk sharing, compensation, benefit distribution, and so on, the stability of the contract is greatly reduced, which leads to the decline of the contract fulfillment rate in the process of agricultural product sales in China. Therefore, how to further improve the degree of repeated transactions, increase investment in fine management, and improve quality level of fruit are significant and important under the background of rising labor cost.

Table 6. Estimated impact of labor cost on farmers' technical investments with different degree of repeat.

\begin{tabular}{|c|c|c|c|c|c|}
\hline \multirow{2}{*}{ Variable } & \multirow{2}{*}{ Symbol } & \multicolumn{2}{|c|}{ OLS } & \multicolumn{2}{|c|}{ 3SLS } \\
\hline & & Coefficient & $T$-Values & Coefficient & T-Values \\
\hline \multicolumn{6}{|c|}{ 1. Investment of Fine Management Function Estimate } \\
\hline Interaction & $w \times N$ & 0.007 & -0.2 & $0.015^{* * *}$ & 4.41 \\
\hline Price of labor & $w$ & $-0.036^{* *}$ & -2.47 & $-0.102^{* * *}$ & -6.96 \\
\hline Elder group & old & 0.693 & -0.63 & 0.962 & -0.94 \\
\hline Number of people in the labor & $l a b$ & $2.535^{* * *}$ & -10.96 & $2.299 * * *$ & -7.43 \\
\hline Education level & $e d u$ & -0.682 & -1.28 & -0.438 & -0.87 \\
\hline Number of training & tec & 0.854 & -0.84 & 0.25 & -0.26 \\
\hline Experience for plantation & time & $0.136^{* *}$ & -2.09 & $0.129 * *$ & -2.09 \\
\hline Share of cultivation income & inc & -0.109 & -0.12 & 0.179 & -0.21 \\
\hline Risk preferences & risk & -0.496 & -1.34 & $-0.742 * *$ & -2.13 \\
\hline Type of farmer & type & -0.004 & -0.73 & -0.003 & -0.36 \\
\hline Plant area & size & 1.276 & -1.33 & 0.746 & -0.83 \\
\hline Age of peach tree & age & $0.306^{* * *}$ & -2.68 & $0.250 * *$ & -2.26 \\
\hline Plant Density & den & 0.015 & -1.28 & 0.0121 & -1.09 \\
\hline East regions & $p l a_{1}$ & $3.890^{* * *}$ & -3.16 & $3.931^{* * *}$ & -3.29 \\
\hline Central regions & $\mathrm{pla}_{2}$ & -0.209 & -0.16 & -0.664 & -0.54 \\
\hline Constant & cons & -1.734 & -0.59 & -0.488 & -0.17 \\
\hline R-squared & & \multicolumn{2}{|c|}{0.7382} & \multicolumn{2}{|c|}{0.6228} \\
\hline Prob $>$ F & & \multicolumn{2}{|c|}{0.0000} & \multicolumn{2}{|c|}{0.0000} \\
\hline \multicolumn{6}{|c|}{ 2. Degree of Repeat Transactions Function Estimate } \\
\hline Investment of Fine Management & $\mathrm{H}$ & -0.00305 & -0.22 & -0.0651 & -1.36 \\
\hline Sales time of peaches & per & $0.153^{* * *}$ & -15.95 & $0.069 * * *$ & -9.96 \\
\hline Input of organic fertilizer & org & -0.001 & -1.55 & $-0.001^{* * *}$ & -3.02 \\
\hline Average selling price & pri & -0.023 & -0.29 & 0.015 & -0.28 \\
\hline $\begin{array}{l}\text { Regional public or independent } \\
\text { brands }\end{array}$ & bra & 1.420 * & -1.72 & $0.382 * * *$ & -3.69 \\
\hline Concentration of dealers & $h h i$ & -0.049 & -0.09 & -0.199 & -0.54 \\
\hline Constant & _cons & $2.856^{* * *}$ & -3.5 & $6.908^{* * *}$ & -10.22 \\
\hline R-squared & & \multicolumn{2}{|c|}{0.3304} & \multicolumn{2}{|c|}{0.4474} \\
\hline Prob $>$ F & & \multicolumn{2}{|c|}{0.0000} & \multicolumn{2}{|c|}{0.0000} \\
\hline
\end{tabular}

\section{Conclusions and Policy Implications}

This paper proposes a way to deal with increase of labor cost to improve sustainability by using estimated results. It focuses on the degree of repeated transactions and use of fine management aspects of sustainability, which can improve the sustainable development of fruits. Based on studies that were carried out, only through improving investment of fine management and quality of fruits, 
can farmers turn the challenges into opportunities for development. This paper mainly draws the following conclusions:

The coefficient of labor cost is significant at the $1 \%$ confidence level. Foreseeably, for apple, peach, and other fruit trees that require flower/fruit thinning and pruning, with rising labor costs, the farmers will experience a continued decline in their investment in fine management, such as fruit/flower thinning and pruning. It is a relief that the degree of repeated transactions has a direct positive effect on the labor investment. For farmers with relatively lower degrees of repeat transactions, as the labor cost increases, they will significantly reduce their labor investment in fine management. As one of the ways to significantly improve the degree of repeated transactions, the construction of agricultural product brand has long been one of vital tasks for government. With the policy and financial support, there has been a group of well-noted national and regional agricultural product brands of which most are regional public brands. However, it cannot be ignored that because of the high regulatory cost of regional public brands, farmers can easily obtain higher profits by labeling the different kinds of agricultural products, resulting in the loss of consumer interests and impact of regional brands. By contrast, the company's brand can effectively reduce or even avoid the negative externalities produced by farmers who misuse the regional public goods' brand. Therefore, the support for agricultural product brand can gradually focus on private brand rather than traditional public brand in the future development of agricultural product brand. While encouraging and supporting the establishment of a private agricultural products brand, the support funds should be focused on subsidizing protection and discrimination of enterprises' own brands. The government can also help enterprises improve protection of brand by providing packaging and anti-counterfeit labels for enterprises. In addition, the government should not only strengthen supervision and management of agricultural products, but also help enterprises to combat brand-counterfeiting, especially cross-regional and organized brand-counterfeiting, curbing the occurrence of trademark counterfeiting. Lastly, the government could focus on the establishment of networks of companies, aimed at sharing skilled labor for the execution of quality work and for the creation of professional training programs, enjoying the benefits of scale economy on production cost.

Author Contributions: C.C. conceived and designed the experiments; B.Y. performed the experiments, analyzed the data, and contributed analysis tools; B.Y. wrote the paper; C.C. revised the paper.

Funding: This research was funded by the National Modern Agricultural Industry Technical System Construction Special Funds (Grant Number CARS-30), The China Postdoctoral Science Foundation (Grant NumNumber 2019M652486), The Project of Qingdao Social Science Planning Research, Project of Shandong Social Science Planning Research and The Fundamental Research Funds for the Central Universities.

Conflicts of Interest: The authors declare no conflict of interest.

\section{References}

1. Zhong, F.N. Understanding Issues Regarding Food Security and Rising Labour Cost. Agric. Econ. 2016, 1, 23-24.

2. Caswell, J.A.; Mojduszka, E.M. Using informational labeling to influence the market for quality in food products. Am. J. Agr. Econ. 1996, 78, 1248-1253. [CrossRef]

3. Giacconel, V.; Ferril, M. Microbiological quantitative risk assessment and food safety. Vet. Res. Commun. 2005, 29, 101-106. [CrossRef] [PubMed]

4. Banker, R.D.; Khosla, I.; Sinha, K.K. Quality and competition. Manag. Sci. 1998, 9, 1179-1192. [CrossRef]

5. Halkier, B.; Holm, L.; Domingues, M. Trusting complex quality conscious or unprotected? constructing the food consumer in different European national contexts. J. Cons. Cul. 2007, 3, 379-402. [CrossRef]

6. Foster, J.; Thomas, S. Towards an understanding of supply chain quality management. J. Oper. Manag. 2008, 4, 461-467. [CrossRef]

7. Yuan, B.; Zhan, J.T.; Chen, C. Evolution of a development model for fruit industry against background of an aging population: Intensive or extensive adjustment? Sustainability 2018, 1, 1095. [CrossRef] 
8. Liu, H.; Zhang, W. The significance and technical essentials of pruning fruit trees. China Hortic. Abs. 2014, 8, 207-208.

9. Wang, X.F.; Meng, Y.P.; Cao, Q.F. Advances in apple chemistry and fruit thinning. J. Fruit Sci. 2006, 2, 437-441.

10. Daeyoung, K.; Soyoon, K.; Yongjoon, K. An Empirical Assessment of the Economic Damage Caused by Apple Marssonina Blotch and Pear Scab Outbreaks in Korea. Sustainability 2015, 7, 16588-16598.

11. Nadeem, A.A.; Irfan, A.; Ishfaq, A.H. Effects of Putrescine Application on Peach Fruit during Storage. Sustainability 2019, 11, 2013.

12. Wang, Z.; Song, Y.Z.; Liu, H. China's fruit tree pruning machinery research status and development trends. J. Agric. Mech. 2017, 3, 126-130.

13. Feng, X.Y. High-yield high-quality peach cultivation. Liaoning Sci. Tech. Press 2010, 9, 56-62.

14. Giri, B.C.; Chakraborty, A. Quality and pricing decisions in a two-echelon supply chain under multi manufacturer competition. Int. J. Adv. Manuf. Technol. 2015, 9, 1927-1941. [CrossRef]

15. Shi, H.Y.; Liu, Y.; Petruzzi, N.C. Consumer heterogeneity product quality and distribution channels. Manag. Sci. 2013, 5, 1162-1176. [CrossRef]

16. Arora, N.; Henderson, T. Noncompensatory dyadic choices. Mark. Sci. 2011, 6, 1028-1047. [CrossRef]

17. Wang, X.Y.; Fu, K. Commitment, consumer choice and product quality level: An equilibrium analysis based on corporate social responsibility. J. Econ. Res. 2013, 8, 94-106.

18. Fu, J.T.; Ji, Y.Q. Does new-round Land Confirmation, Registration and Certification Boost the Land Transfer among Farmers? An Empirical Evidence from 3 Counties in Jiangsu Province. J. Nanjing Agric. Univ. 2016, 1, 105-113.

19. Zhu, W.J.; Luo, B.L. The Formation of Farmland Endowment Effect and Its Object Discrimination. Agro. Tech. Econ. 2019, 4, 4-15.

20. Holden, S.; Lunduka, R. Do fertilizer subsidies crowd out organic manures? The case of Malawi. Agric. Econ. 2012, 3, 303-314. [CrossRef]

21. Yang, H. On the Small Peasant Economy with Chinese Characteristics. Agric. Econ. 2016, 7, 60-73.

22. Du, P. Social Small Farmers: The social basis for the development of small-scale peasant economy: Based on the agricultural development in jianghan plain. China Agric. Econ. 2017, 1, 57-65.

23. Huang, Z.H.; Fu, L.L.; Li, H.T. Supply—Side Structural reform of China's Agriculture: Retrospect, Problems and reforms. J. Nanjing Agric. Univ. 2016, 6, 1-5.

24. Jiang, C.Y.; Du, Z.X. Thoughts on promoting supply-Side structural reform of agriculture. J. Nanjing Agric. Univ. 2017, 1, 1-10.

25. Roland, T.R.; Richard, M. Mathematical models of service. Eur. J. Oper. Res. 2006, 5, 427-439.

26. Safari, F.; Safari, N. Customer Lifetime Value Determination Based on RFM Model. Mark. Intell. 2016, 4, 446-461. [CrossRef]

27. Van, D.M.; Marc, F. Using revisions as a measure of price index quality in repeat-sales models. J. Real Estate Financ. 2019, 2, 1-40.

28. Dreiman, M.H.; Anthony, P.C. Alternative methods of increasing the precision of weighted repeat sales house prices indices. J. Real. Estate Financ. 2004, 4, 299-317. [CrossRef] 